\title{
A suspected case of hunting accident. Case report
}

\author{
S Procaccianti ${ }^{1}$, L.V. Pascali ${ }^{2}$, V Triolo ${ }^{1 *}$, A Bonifacio $^{1}$ and P Procaccianti ${ }^{1}$ \\ ${ }^{1}$ Department of Biotechnology and Legal Medicine - Section of Legal Medicine - University of Palermo, Italy \\ ${ }^{2}$ Institute of Legal Medicine, University of Cattolica S. Cuore, Rome, Italy
}

\begin{abstract}
Nowadays, the use of molecular biology in forensics has made it possible to identify human victim and sometimes even the circumstances under which the death occurred through. In our case, a corpse of a 50-years old man with a gunshot wound was found in the woods.
\end{abstract}

The suspected murderer declared that it had been a hunting accident while he shot a wild boar. During the autopsy, a bullet (Borra-bullet Gualandi, $32 \mathrm{gr}$ ) was found in the abdomen of the victim.

The authors investigated the presence of boar and victim blood both on the bullet, in order to substantiate the thesis of the hunting accident.

Laboratory investigations underscored the presence of human cellular material on the bullet, which corresponds to profile of the victim and human and porcine ribosomal DNA.

Through this investigation, the authors showed that it was a hunting accident, because the bullet passed through the body of the boar before hitting the victim.

\section{Introduction}

In June 2003, a corpse of a 50-years old man with a gunshot wound in abdomen was found in woods of Messina. Near him, there was a dead wild boar. After the discovery, the man's body was subjected to autopsy: there was only a bullet in his abdomen, nothing else was found.

The court suspected a homicide, but the suspect stated to be a hunting accident while he's shot a wild boar .

At that moment, was not followed a protocol for the collection of biological material from bullet.

Unfortunately, during the autopsy, the projectile was washed and only at a later time it was treated by the forensic police, in order to collect the cellular human material.

The investigations of forensic police allowed exclusive to confirm the presence of victim's blood in the bullet.

These initial investigations did not allow to understand if it was a murder or a hunting accident.

Therefore, after one year, the Court has decided to entrust the task to new experts.

We intervened at a third time, as advisors to the Court, but the previous treatments, as washing of the bullet, made more difficult to find traces biological material. bullet.

We were afraid of not being able to extract useful sample by the

The purpose of this work was the extraction of DNA from a repeatedly pre-treated sample and to determine the presence of wild boar and victim blood both on the bullet, in order to substantiate the thesis of the hunting accident.

In the last decade, the analysis of polymorphic profiles of human DNA has played an important role in forensics. As is well known, it is possible to have many copies of DNA from also a little biological sample $[1,2,3]$.

The use of molecular biology in forensics has made it possible to identify human victim and sometimes even circumstances of death.
It is known, also, that the death by gunshot wound, particularly during the hunting, may pose some questions. One of the most important problem is to identify the dynamics of events, in order to distinguish between accident and homicide and a careful examination of the probable crime scene may be useful to clarify the circumstances.

Also in Italy, the DNA testing has played a central role in court, for example in order to exclude or confirm a suspicion during crime investigations.

\section{Material and Methods}

During autopsy, a Borra-bullet Gualandi, $32 \mathrm{gr}$ (fig.1) was found in the abdomen of the victim.

This bullet was thoroughly washed and cleaned and collected in a separate plastic tube. Victim blood was also collected, in order to typing his genetic profile.

Shortly after the autopsy, the bullet has been treated by the forensic police, in order to collect cellular human material. Their investigation showed only the presence of human cells, corresponding to the genetic profile of the victim.

Because of uncertain results, after one year, the Court requested further investigations to better understand the dynamics of events.

Washing of the bullet before the extraction of biological material

*Corresponding author: Valentina Triolo, Department of Biotechnology and Lega Medicine - Section of Legal Medicine - University of Palermo, Italy, Tel: +39091 6553284; Fax: 0916553203; E-mail: dr.valentinatriolo@hotmail.it

Received December 08, 2010; Accepted December 28, 2010; Published December 30, 2010

Citation: Procaccianti S, Pascali LV, Triolo V, Bonifacio A, Procaccianti P (2010) A suspected case of hunting accident. Case report. J Forensic Res 1:111. doi:10.4172/2157-7145.1000111

Copyright: (C) 2010 Procaccianti S, et al. This is an open-access article distributed under the terms of the Creative Commons Attribution License, which permits unrestricted use, distribution, and reproduction in any medium, provided the original author and source are credited. 
is contra-indicated but, in our case, despite washing of the bullet, it was possible to extract the material for forensic investigations.

The bullet was incubated in bottle of $50 \mathrm{ml}$ with stain lysis buffer, until filled; supplemented periodically with $\mathrm{pK} 20 \mathrm{mg} / \mathrm{ml}$. Incubation was conducted at $56{ }^{\circ} \mathrm{C}$ overnight. The protein matrix was removed with 2 passages in phenol / chloroform / isoamyl alcohol (Sambrook et al. 1989); slow emulsion of two phases, and final passage in chloroform / isoamyl alcohol. The extracted DNA was precipitated in cold absolute ethanol, freeze-dried and resuspended in $50 \mu \mathrm{l}$ of sterile distilled water.

The extracted DNA was amplified using the Applied Biosystem AmpIFISTR identifier PCR kit in a $25 \mu \mathrm{l}$ final reaction volume and the sample was amplified on an applied biosystems GeneAmp ${ }^{\circledR P C R}$ system 2400 Thermal cycler.

Systems D81179, D21S11, D7S820, CSF1PO, D3S1358, TH01, D13S317, D16S539, D2S1338, D19S433, vWA31A, TPOX, D18S51, D5S818, FGA, Amelogenin were used.

The technique used for the diagnosis of ribosomal DNA is based on enzymatic amplification of the chosen sequence by PCR. Then, the fragments was analyzed with semi-automatic procedure using a capillary sequencer $(\mathrm{AB})$ and the known controls of the analyzed species. The genetic profile of the victim and the wild boar blood (extracted from muscle) were used as controls. In our case has been analyzed fragment coding for $28 \mathrm{~S}$.

\section{Results}

The analysis of DNA extracted from the projectile was accomplished with two different protocols for gene amplification and has allowed the identification of biological material human cells, corresponding to the genetic profile of the victim, ribosomal DNA of porcine origin and of human origin (the latter a large prevalence). Indeed, from the extract that corresponds to the findings, were amplified two different fragments.

One of fragments is identical to the amplified human of victim, the second fragment is identical to amplified DNA obtained from pigs, used as a standard.

Then, we compared the material extracted with samples available for victim and boar (the results in the table 1 and 2). In table 1 , autosomal microsatellites profiles of victims are compared with those found in the material extracted by projectile. In table 2 , human ribosomial DNA and of the sus scrof are compared with those found in the bullet.

DNA extracted by cellular human material and ribosomal DNA corresponds to genetic profile of the victim. The unknown ribosomal DNA corresponds to samples of a boar.

\section{Discussion}

Both the victim's DNA profile and the animal ribosomal DNA determined from biological material on the bullet found in the victim's abdomen, confirming that the bullet had perforated the victim and the animal.

The STR-based individualisation of biological deposits on bullets after perforation of tissue may be useful to identify the person injured or killed $[4,5]$ and, as in our case, to reconstruct the dynamics of events. Typing of DNA has been shown to be useful in difficult cases, particularly when the biological material is very low, as in this case.

Some study suggested that DNA should be used for typing of human tissue traces on bullets. Generally, some Authors showed that the base is preferential location to found the cells on bullets.

In our case, it was not possible to extract blood or other biological material directly from the projectile, so distillate water washing was used.

Despite the scarcity of material, the collection of biological material through the water washing of the sample was sufficient to obtain the material useful in investigations.

In our case, we had the need to identify not only the human victim's DNA, but also the animal DNA; moreover, it was necessary to identify the animal species.

The identification of various species is an important issue in forensics, particularly in this case.

The efficient discrimination of species is possible analysing some genomic regions of the mitochondrial DNA (mtDNA) and ribosomal DNA (rRNA). In addition, it is known that the ribosomal DNA has regions of variation between species. Naito et al. demonstrated that these regions showed slight differences between species [6].

It is well known that ribosomal genes of vertebrates are organized into clusters repeated and scattered in many chromosomes and encode three DNA molecules in ribosome called 16S, 5S and 28S. The fragment coding for $28 \mathrm{~S}$ presents regions variables, some of which are significantly different in size between diverse animal species $[6$, $7,8,9,10,11]$.

Typing this specific ribosomal gene is therefore useful for molecular identification of an animal species. It is also known that the ribosomal DNA is specific for the Sus Scrofa or Sus domesticus species (pig or wild boar). Ribosomal DNA of the domestic pig and wild boar, both belonging to the species Sus scrofa and Sus domesticus, is identical.

The fragment coding for $28 \mathrm{~S}$ have a variable number of regions, some of which are significantly different in size between different species. Each species is invariably connotes for its fragment. The typing of this specific ribosomal gene is therefore useful for the molecular identification of species. Some Authors revealed that this sequences have sensitivity and specificity to identify species.

In our case, the fragment found in biological material of bullet was consistent with that extracted from the blood of pigs, used as reference standard.

\section{Conclusion}

Forensic genetics has an extremely important impact on the society by providing reliable evidence both for exonerating the innocent and for convicting the perpetrator.

The DNA analysis of tissue deposits on bullet represents sensitive methods capable of individualizing minute traces transferred during perforation of human and animal body.

Despite the many treatments he has been receiving the bullet, we were able to collect the biological material by the bullet and rebuild the likely events. Common biological material was found on the bullet: verisimilar animal and human. Through this investigation, the authors showed that it was a hunting accident, because the bullet passed through the body of the boar before hitting the victim.

In the our case, the crime scenes helped the investigators, but DNA typing of biological material on the perforating bullets proved 
Citation: Procaccianti S, Pascali LV, Triolo V, Bonifacio A, Procaccianti P (2010) A suspected case of hunting accident. Case report. J Forensic Res 1:111. doi:10.4172/2157-7145.1000111

Page 3 of 3

decisive in the reconstruction of the crime scenes, as in other cases described in literature [12].

\section{References}

1. Carracedo (2005) Forensic DNA Typing Protocolos (methods in molecular biology). 297 Human Press Inc.

2. Schneider PM (1997) "Basic issues in forensic DNA typing". Forensic Science Internation 88: 17-22.

3. Schneider PM (2007), "Scientific standards for studies in forensic genetics". Forensic Science International 165: 238-243.

4. Karger B, Stehmann B, Hohoff C, Brinkmann B (2001) "Trajectory reconstruction from trace evidence on spent bullets II. Are tissue deposits eliminated by subsequent impacts?". International Journal of Legal Medicine 114: 343-345.

5. Knudsen PJT (1993) Citology in ballistics. An experimental investigation of tissue fragments on full metal jacketed bullets using routine cytological techniques. In J Legal Med 106: 15-18.

6. Bellis C, KJ Ashton, L Freney, B Blair, LR Griffiths (2003) "A molecular genetic approach for forensic animal species identification". Forensic Science Intrernational 134: 99-108.
7. Kazuhiko Imaizumi, Tomoko Akutsu, Sachio Miyasaka, Mineo Yoshino (2007) "Development of species identification tests targeting the 16S ribosomal RNA coding region in mitochondrial DNA". International Journal of Legal Medicine Volume 121: 184-191.

8. Lin CS, Yu-Lin Sun, Chang-Yeu Liu, Ping-Cheng Yang, Ling-Chu Chang, et al. (1999) "Complete nucleotide sequence of pig (Sus scrofa) mitochondrial genome and dating evolutionary divergence within Artiodactyla". Gene 236: 107-14.

9. Ursing BM, Arnason U (1998) "The complete mitochondrial DNA sequence of the pig (Sus scrofa)". J Mol Evol 47: 302-6.

10. Kazumi Ono, Motonobu Satoh, Touho Yoshida, Yutaka Ozawa, Arihiro Kohara et al. (2007) "Species identification of animal cells by nested PCR targeted to mitochondrial DNA". In Vitro Cellular \& Developmental Biology - Animal 43 168-175.

11. Budowle B, Paolo Garofano, Andreas Hellman, Melba Ketchum, Sree Kanthaswamy, et Al. (2005) "Recommendation for animal DNA forensic and identity testing”. Internal Journal Legal Medicine 119: 295-302.

12. Samuel TG, Ferreiraa Aluisio Trindade-Filhoa, Karla A Paulaa, Cláudia $R$ Mendesa Flávia A Maiaa, et al. (2009) "DNA analysis of biological materia on perforating bullets and crime scene reconstruction. Forensic Science International: Genetics Supplement Series 2: 213-214. 